\title{
Supply of a Nondrug Substitute Reduces Escalated Heroin Consumption
}

\author{
Magalie Lenoir' and Serge H Ahmed*, \\ 'University Victor-Segalen Bordeaux2, CNRS UMR 5227, 146 rue Léo-Saignat, Bordeaux, France
}

\begin{abstract}
Escalation of drug consumption - a hallmark of addiction — has been hypothesized to be associated with a relative devaluation of alternative nondrug rewards and thus with a decrease in their ability to compete with or to substitute for the drug. In a behavioral economic framework, decreased substitutability of nondrug rewards for drug would explain why drug consumption is behaviorally dominant and relatively resistant to change (eg price-inelastic) in drug-addicted individuals. The goal of the present study was to test this hypothesis using a validated rat model of heroin intake escalation. Escalation was precipitated by long (6h, long access ( $\operatorname{Lg} A)$ ), but not short (I h, short access (ShA)), daily access to i.v. heroin self-administration. After escalation, the effects of price (ie fixed-ratio value) on heroin consumption were assessed under two alternative reward conditions: in the presence or absence of a nondrug substitute for heroin (ie four freely available chow pellets). As expected, escalated heroin consumption by $\operatorname{LgA}$ rats was less sensitive to price than heroin consumption by ShA rats, showing that heroin had acquired greater reinforcing strength during escalation. However, supplying a substitute during access to heroin was sufficient to reverse this post-escalation increase in the reinforcing effectiveness of heroin. Thus, escalated heroin consumption is not associated with a decreased sensitivity to competing nondrug rewards. Escalated drug use may therefore persist, not so much because of a relative devaluation of nondrug substitutes, but because of a loss or reduction of their availability.

Neuropsychopharmacology (2008) 33, 2272-2282; doi: I0. 1038/sj.npp. I 30 I602; published online 31 October 2007
\end{abstract}

Keywords: behavioral economics; choice; substitutability; demand elasticity; progressive ratio

\section{INTRODUCTION}

A critical goal of drug addiction research is to elucidate the factors that contribute to the development and maintenance of escalated drug use. Based on previous research on continuous access to drug self-administration (Deneau et al, 1969; Johanson et al, 1976; Bozarth and Wise, 1985; Wolffgramm, 1991), we and others have recently developed and begun to validate an animal model of the transition to escalated drug use (reviewed in Ahmed, 2005). Differential access to i.v. stimulant or opiate self-administration produces two patterns of drug intake. With $1 \mathrm{~h}$ of access per day (short access or ShA), rate of drug intake is low and stable over time. In contrast, with 6 or more hours of access per day (long access or $\operatorname{LgA}$ ), rate of drug intake gradually escalates above initial levels (Ahmed and Koob, 1998; Ahmed et al, 2000; Mantsch et al, 2001; Paterson and Markou, 2003; Walker et al, 2003; Ferrario et al, 2005; Liu et al, 2005; Perry et al, 2006). The intensity of drug intake escalation is influenced by both the unit dose and the daily

*Correspondence: Dr SH Ahmed, University Victor-Segalen Bordeaux2, CNRS UMR 5227, 146 rue Léo-Saignat, Bordeaux 33076, France, Tel: + 33557 57| 566, Fax: + 33556900 278,

E-mail: sahmed@u-bordeaux2.fr

Received 23 May 2007; accepted 2 I September 2007 duration of drug access (Mantsch et al, 2004; Wee et al, 2007). Finally, once established, escalated levels of drug consumption can persist for several weeks, despite temporally reduced drug availability (Ahmed and Koob, 1999).

Several theories have been proposed over the years to explain the progression toward escalated drug choice. Despite divergences in proposed mechanisms, most of these theories predict that with repeated drug use, the relative value of the drug will progressively increase while the relative values of other, more socially valued rewards will decrease (for a brief overview, see Ahmed, 2004). One possible consequence of this relative devaluation of alternative rewards would be a reduction of their ability to compete with or to substitute for drugs and thus their ability to turn users away from the pursuit of drugs. According to consumer demand theory, decreased substitutability of nondrug rewards for drug should reduce the demand elasticity of drug, that is the degree to which drug consumption decreases with increases in price or in its behavioral equivalents, such as, for instance, time and/or effort spent in drug seeking (eg Heyman, 1996; Samuelson and Nordhaus, 1998). This increased inelasticity of drug demand would in turn manifest as allocation of an increasingly large proportion of their income (or time/ effort) to drugs and/or to seeking other sources of income, including risky and illegal ones (Eatherly, 1974; Miron and 
Zwiebel, 1995; Samuelson and Nordhaus, 1998). Thus, decreased substitutability of nondrug rewards for drug may represent a potential candidate mechanism that explains why drug consumption ultimately becomes behaviorally dominant and resistant to change following prolonged drug use.

In laboratory animals, price can be modeled by the response requirement per reinforcement in operant conditioning tasks, such as, for instance, the fixed ratio (FR) in FR schedules. Since a specific behavioral response (eg lever pressing) takes time and is effortful, increasing the response requirement amounts to an increase in the behavioral cost of the reinforcer. Indeed, previous research showed that consumption of a reinforcer decreased with increases in response requirement in a manner that recalls the effects of price on consumption of an economic good (Lea, 1978; Allison, 1979; Hursh, 1980). For instance, Hursh et al, 1988 observed that the demand for food is initially inelastic with increasing response requirements (ie food consumption decreases less than price increases) and then becomes elastic above a specific response requirement (ie food consumption decreases more than price increases). Importantly, the demand for food is influenced by the availability of substitutes for food (eg Lea and Roper, 1977; Bauman et al, 1996; Collier and Johnson, 2000). For instance, Lea and Roper (1977) showed in a two-compartment operant chamber that food consumption in one chamber was more sensitive to increases in response requirement when food was available in the other chamber. This early work showed that operant behavior in animals is fully amenable to a classical microeconomic analysis, and it launched the now mature field of behavioral economics. For convenience, the expressions 'price' and 'response requirement' will be used interchangeably in the following text.

A behavioral economic approach has also been recently applied with success to analyze drug consumption in laboratory animals (Bickel et al, 1990, 1995; Hursh, 1991). As with the consumption of nondrug reinforcers, the consumption of drugs (eg ethanol, phencyclidine, cocaine, heroin) decreases in the face of increasing prices in both rats (eg Comer et al, 1996; Solinas et al, 2004; Heyman et al, 1999) and monkeys (Carroll et al, 1991; Rodefer and Carroll, 1996, 1997; Ko et al, 2002) (for a general review, Bickel et al, 1995). In the majority of studies, the demand for drug is initially inelastic to changes in price and then becomes elastic above a certain price, called $P_{\max }$ (Hursh, 1991; Bickel et al, 2000). Importantly, the demand for drug becomes even more elastic when nondrug rewards are available during drug access (Carroll et al, 1991, 1995; Comer et al, 1996; Rodefer and Carroll, 1996, 1997). For instance, Carroll et al (1991) showed in monkeys that supplying a sweetened drink during access to oral phencyclidine considerably elevated the degree to which the consumption of phencyclidine decreased with increasing prices. This seminal research demonstrated that foodrelated rewards can function as substitutes for different drugs of abuse and, as such, their availability during drug access can profoundly alter the demand for drugs in laboratory animals.

Most of this research was conducted in animals that had not escalated their drug intake as they had limited access to the drug. Whether drug consumption becomes more inelastic and less sensitive to available substitutes after prolonged access to the drug remains to be established. The goal of the present study was to address this question by comparing the effects of food on heroin demand in both ShA and LgA rats. After escalation, heroin demand curves were generated within-session by increasing the unit price of heroin (FRs 1, 2, 4, 8, 12, and 16) every $30 \mathrm{~min}$. The elasticity of heroin demand was then measured by estimating $P_{\max }$, the price that corresponds to the maximal rate of responding or response output (ie $O_{\max }$ ) and above which the demand of drug shifts from inelastic $(0>$ slopes $>-1)$ to elastic (slopes $<-1$; Hursh, 1991; Bickel et al, 2000). Thus, the higher the $P_{\max }$, the larger the range of prices in which heroin demand is inelastic. Any postescalation change in $P_{\max }$ will therefore indicate that escalated heroin demand is inelastic over a wider range of prices. For convenience, we will hereafter refer to this phenomenon as a mere increase in demand inelasticity. After completion of the behavioral economic analysis of heroin demand, the effects of food on heroin selfadministration were also tested under a progressive-ratio (PR) schedule. In the PR procedure, response requirements progressively increase within-session after each heroin selfinjection until operant responding stops. The last completed response requirement is called the break point and is thought to be functionally analogous to $P_{\max }$ in that both the break point and $P_{\max }$ measure the reinforcing strength of drugs (Rodefer and Carroll, 1997; Bickel et al, 2000; Greenwald and Hursh, 2006).

\section{MATERIALS AND METHODS}

\section{Subjects}

A total of 24 naïve, young adult, male, Wistar-Han rats were used, weighing 224-266 g prior to surgery (Charles River, France). Rats were housed in groups of two or three and were maintained in a light- (12-h reverse light-dark cycle; lights on at 09 p.m.) and temperature-controlled vivarium $\left(23 \pm 2{ }^{\circ} \mathrm{C}\right)$. All behavioral testing occurred during the dark phase of the light-dark cycle. Food (ie chow pellets) and water were freely available in the home cages throughout the duration of the experiment. Thus, rats had continuous access to food and water immediately upon return to their home cages at the end of each testing session. Otherwise rats had no access to food during heroin access, except when specified (see below, for details). All experiments were carried out in accordance with institutional and international standards of care and use of laboratory animals (UK Animals (Scientific Procedures) Act, 1986; and associated guidelines; the European Communities Council Directive (86/609/EEC, 24 November 1986) and the French Directives concerning the use of laboratory animals (décret 87-848, 19 October 1987)).

\section{Apparatus}

A total of 12 identical operant chambers $(30 \times 40 \times 36 \mathrm{~cm})$ were used for all behavioral training and testing (Imétronic, France). All chambers were located away from the colony room in a dimly lit room. They were individually enclosed in wooden cubicles equipped with a white noise speaker 
( $45 \pm 6.2 \mathrm{~dB}$ ) for sound-attenuation and an exhaust fan for ventilation. Each chamber had a stainless-steel grid floor (rod diameter: $6 \mathrm{~mm}$; inter-rod distance: $16 \mathrm{~mm}$ ) that allowed waste collection in a removable tray containing maize sawdust. Each chamber consisted of two opaque operant panels on the right and left sides, and two clear Plexiglas walls on the back and front sides. Two retractable levers $(2 \times 4 \times 1 \mathrm{~cm}$; Imétronic, France $)$ were mounted on different panels: one on the middle of the left panel, the other on the middle of the right panel. In this spatial configuration, there was no initial preference for either lever. Each lever was mounted $7 \mathrm{~cm}$ above the grid floor and protruded from the wall $2 \mathrm{~cm}$ (when extended). A white light diode $(1.2 \mathrm{~cm}$ OD) was mounted $8.5 \mathrm{~cm}$ above each lever (from the center of the diode). Each lever was connected to a syringe pump (Imétronic, France) placed outside, on the top of the cubicle. To increase precision, the syringe pump delivered drug solution in discrete fixed volumes (37 $\mu \mathrm{l}$ with $20-\mathrm{ml}$ syringes), with one unit volume delivered within approximately $1 \mathrm{~s}$. Drug solution was delivered through a Tygon tubing (Cole Parmer, IL, USA) connected via a single-channel liquid swivel (Lomir Biomedical Inc., QC, Canada) to a cannula connector (Plastics One, Roanoke, VA) on the back of the animal. The Tygon tubing was protected by a stainless steel spring $(0.3 \mathrm{~cm} \mathrm{ID,} 0.5 \mathrm{~cm} \mathrm{OD)}$ (Aquitaine Ressort, France) which was suspended at the center of the chamber from the swivel tether connector. Vertical movements of the animal were compensated for by means of a counterbalancing weightpulley device (Imétronic, France).

\section{Surgery}

Anesthetized rats (Chloral hydrate, $500 \mathrm{mg} / \mathrm{kg}$ IP) (J-T Baker, the Netherlands) were prepared with silastic catheters (Dow Corning Corporation, Michigan, USA) in the right jugular vein that exited the skin in the middle of the back about $2 \mathrm{~cm}$ below the scapulae. After surgery, catheters were flushed daily with $0.15 \mathrm{ml}$ of a sterile antibiotic solution containing heparinized saline $(280 \mathrm{IU} /$ $\mathrm{ml}$ ) (Sanofi-Synthelabo, France) and Totapen (BristolMyers-Squibb, France). When a catheter leakage was suspected (eg following observation of an extinction-like pattern of drug self-administration), the patency of the catheter was checked by an i.v. administration of Hypnomidate (etomidate, $1 \mathrm{mg} / \mathrm{kg}$ ), a short-acting non-barbiturate anesthetic (Braun Medical, France).

\section{Differential Access to i.v. Heroin Self-Administration}

After 1 week i.v. catheterization, rats were tested for heroin self-administration during two consecutive phases: a screening phase (1 session) and an escalation phase (27 sessions) (see below). There was no operant training before access to heroin self-administration in the present study. Self-administration sessions began with extension of the two retractable levers. The first response on either lever triggered the countdown to the session ending. Subsequent responding on the left lever (active lever) resulted in the delivery of 1 unit dose of heroin under a FR 1 and initiated a 20-s time-out period signaled by the light cue located above the lever. Responding on the other lever (inactive lever) was counted but had no programmed effect. Note that there was no spontaneous preference for either the left or right lever in our experimental settings (see also, Results). No noncontingent injections of heroin were given, except on rare occasions when a subject failed to respond within the first $10 \mathrm{~min}$ in which case it received two passive injections $20 \mathrm{~s}$ apart.

During the screening phase, rats had access to heroin $(15 \mu \mathrm{g}$ per unit dose delivered in a volume of $74 \mu \mathrm{l})$ during only $1 \mathrm{~h}$. The goal of this phase was to measure the initial operant level of responding on each lever in each rat to form two balanced groups with similar mean levels of responding and mean body weight before differential access to the drug (eg Ahmed et al, 2002; Ahmed and Cador, 2006; Lenoir and Ahmed, 2007). During the escalation phase, one group had access to heroin self-administration for only $1 \mathrm{~h}$ per day (ShA rats, $n=12$ ) and the other group for $6 \mathrm{~h}$ per day ( $\operatorname{LgA}$ rats, $n=12$ ). To speed up the escalation process, the unit dose of heroin available during the past $5 \mathrm{~h}$ of each longaccess session was increased to $60 \mu \mathrm{g}$ (by increasing the injection volume to $296 \mu \mathrm{l}$ ) (Mantsch et al, 2004; Lenoir and Ahmed, 2007; Wee et al, 2007). Self-administration sessions were run 6 days per week.

During the course of the experiment, $4 \mathrm{LgA}$ rats began to self-mutilate during the lost $5 \mathrm{~h}$, a maladaptive behavior described in detail elsewhere (Lenoir and Ahmed, 2007). To prevent this behavior, self-mutilating rats were supplied with six daily regular chow pellets $(5 \mathrm{~g}$ each) during the past $5 \mathrm{~h}$, but not during the first hour, of each long-access session of self-administration. We have previously shown that supplying food abolishes the incidence of self-injurious behavior but is without effect on heroin self-administration under a FR1 schedule (Lenoir and Ahmed, 2007; see also the results of the present study).

\section{Assessing the Effects of a Substitute on Heroin Consumption}

At the end of the escalation phase, heroin demand was assessed using two distinct self-administration procedures (FR and PR procedures) and under two alternative reward conditions (with or without a nondrug substitute, food, for heroin). In the FR procedure, the response requirement to obtain a dose of heroin (or unit-price) was incremented every $33 \mathrm{~min}$ while in the $\mathrm{PR}$ procedure, the response requirement was increased after each heroin injection. The nondrug substitute for heroin consisted of four regular chow pellets $(5 \mathrm{~g}$ each) placed on the grid floor, near the center of the cage (Lea and Roper, 1977). Rats were first tested in the FR procedure (12 sessions) and then in the PR procedure (9 sessions). In both procedures, rats were first tested without food and then with food available. Each food condition was tested at least 3 times in both ShA and $\operatorname{LgA}$ rats. There were 3 testing sessions per week (for duration of testing sessions, see below) alternating with three regular 1-h (ShA rats) or 6-h (LgA rats) sessions of heroin selfadministration.

Each FR session lasted $3 \mathrm{~h} 33 \mathrm{~min}$. During the first $15 \mathrm{~min}$ of each session, heroin was available under a FR1 schedule. Subsequently, the FR value was increased every $33 \mathrm{~min}$ in that order: 1, 2, 4, 8, 12, and 16. Each FR value was in effect during $30 \mathrm{~min}$ and was separated from the preceding one by 
a 3-min blackout period during which the ambient white noise was turned off and levers were retracted. Blackout periods were intended to signal changes in the FR value. This procedure allowed one to measure within a session how heroin consumption (number of injections per $30 \mathrm{~min}$ ) varied as a function of price.

In the $\mathrm{PR}$ procedure, the response requirement was increased by a constant increment of three following each heroin injection (ie $1,4,7,10 \ldots$ ). A linear progression was preferred over a more classical, exponential progression because with the latter, the break point for heroin tends to be very low (Roberts and Bennett, 1993). PR sessions ended when 30 min elapsed without an injection. In general, PR sessions ceased within $3 \mathrm{~h}$. The break point was defined as the last completed response requirement and corresponded to the total number of injections earned during the PR session.

\section{Measurement of Food Intake}

Food intake during access to heroin self-administration in the FR and PR procedures was measured by weighing food pellets immediately before and after testing. There was no attempt to control for food spillage in the present study. Nevertheless, occasional searches for small, uneaten morsels of food in the removable tray below the grid floor of the operant chambers indicated that food spillage was rare in our conditions.

\section{Drugs}

Heroin (3,6-diacetylmorphine $\mathrm{HCl}$ ) (Francopia Sanofi, France) was dissolved in $0.9 \% \mathrm{NaCl}$ and kept in $500-\mathrm{ml}$ sterile bags at room temperature $\left(21 \pm 2^{\circ} \mathrm{C}\right)$. Drug doses were expressed as the weight of the salt.

\section{Data Analysis}

Statistics. During acquisition and escalation of heroin selfadministration, responding on the active lever was expressed in percent of total responding (ie active responding + inactive responding). In both FR and PR procedures, data represented the average over the last three sessions of each food condition. Data were subjected to two- or three-way mixed analyses of variance (ANOVA) with one betweensubjects factor (experimental groups: ShA and LgA groups) and one or two within-subjects factor (self-administration session, food condition, price). All post hoc comparisons for interactions were carried out by the Fisher's LSD test.

Estimation of $\mathrm{P}_{\text {max }}$ and $\mathrm{O}_{\text {max }}$. We attempted to estimate $P_{\max }$ and $O_{\max }$ by fitting individual log-log demand curves to the demand equation formulated by Hursh (1991) (nonlinear regression, method of the least squares, Sigmaplot 2002, version 8.02). However, though this equation generally provides a good description of many, though not all, demand curves (Bickel et al, 2000), the results of the regression analysis led to the computation of aberrant $P_{\max }$ values in several rats (eg negative or excessive). These aberrant findings were also obtained when heroin consumption was expressed in milligram per kilogram. Thus, we were unable to quantitatively estimate $P_{\max }$ and $O_{\max }$ in

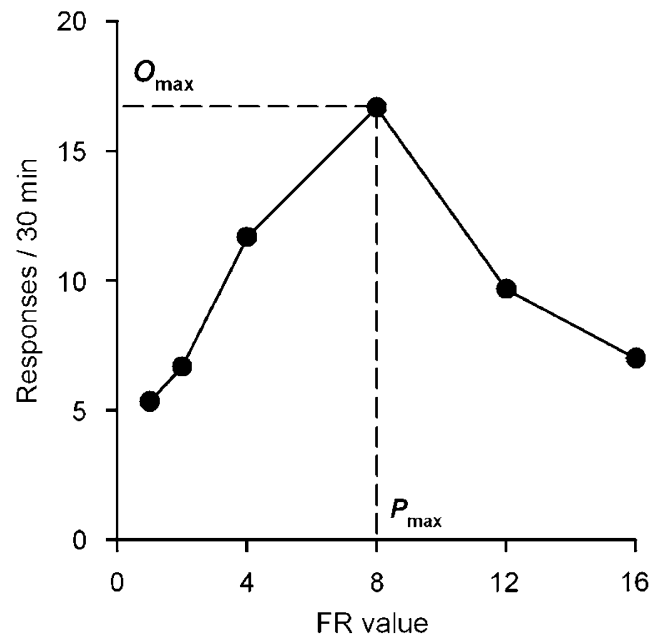

Figure I Graphic estimation of $P_{\max }$ and $O_{\max }$ from actual data obtained in a representative rat. $O_{\max }$ corresponds to the peak of the response output curve and $P_{\max }$ to the price defined by this peak. In the present case, the value of $O_{\max }$ is 16.7 responses per $30 \mathrm{~min}$ and the value of $P_{\max }$ is eight responses per dose.

the present study. Rather, $P_{\max }$ and $O_{\max }$ were determined graphically from individual output curves as described in Figure 1 (see also, Greenwald and Hursh, 2006).

Attrition rate. In the course of the self-administration study, which lasted 4 months, five rats were excluded either because of a failure of catheter patency $(n=4)$ or because of unexplained sudden death $(n=1)$. In the end, there were 10 ShA rats and 9 LgA rats.

\section{RESULTS}

\section{Effects of Prolonged Access to Heroin on Consumption}

To assess the effects of the duration of daily access to heroin ( $1 v s 6 \mathrm{~h}$ ) on heroin self-administration, only data obtained during the first hour were compared between ShA and LgA rats. During screening, there was no initial preference for the active lever in both ShA and LgA rats (active responses amounted to about $50 \%$ of total responses, Figure $2 \mathrm{a}$ ) which did not differ from each other. With repeated sessions, however, both groups developed a large preference for the active lever (about 90\%) (session: $\mathrm{F}(26,442)=8.71$, $p<0.05)$. There was no difference between groups in the level or rate of acquisition of this preference. In contrast, though heroin intake was similar in both groups at the beginning of the escalation phase, with repeated sessions, heroin intake by LgA rats significantly rose above the level of intake by ShA rats (group $\times$ session: $\mathrm{F}(26,442)=17.87$, $p<0.05$ ) (Figure 2b). Post hoc comparisons showed that significant differences between groups appeared from session four onward (Fisher's LSD test, $p<0.05$ ). Post hoc comparisons also revealed that heroin intake in ShA rats began to increase slightly, though significantly, above that measured on day 1 from day 17 onward (Fisher's LSD test, $p<0.05$ ) (not shown). In LgA rats, heroin intake during the lost $5 \mathrm{~h}$ also increased from a mean of $12.7 \pm 1.3$ on day 1 to $22.9 \pm 1.9$ injections of doses of $60 \mu \mathrm{g}$ on day 28 $(\mathrm{F}(26,208)=2.22, p<0.05)$. 

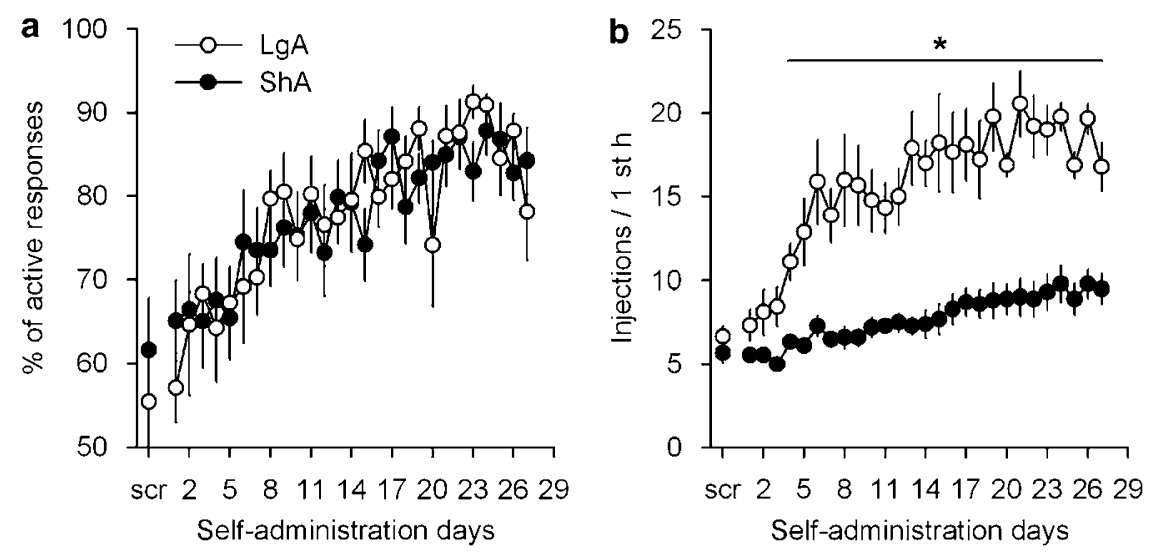

Figure 2 Effects of drug access time on first hour heroin self-administration. Data (mean \pm SEM) represent the percent of responses on the active lever (a) and the number of heroin injections (b) during the first hour. Rats were tested for heroin self-administration (I $5 \mu \mathrm{g}$ per injection) during two consecutive phases: a screening phase (scr, one I-h session) and an escalation phase (27 sessions). During the escalation phase, rats had access to heroin during either I $\mathrm{h}$ (short access $(\mathrm{ShA})$ rats, $n=10$ ) or $6 \mathrm{~h}$ per day (long access $(\mathrm{LgA})$ rats, $n=9$ ). Sessions of heroin self-administration were performed 6 days per week. *Different from ShA rats $(p<0.05)$.

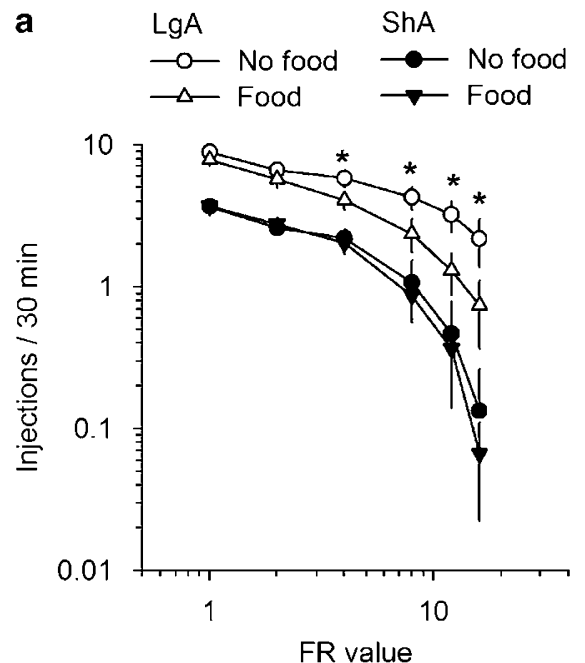

b

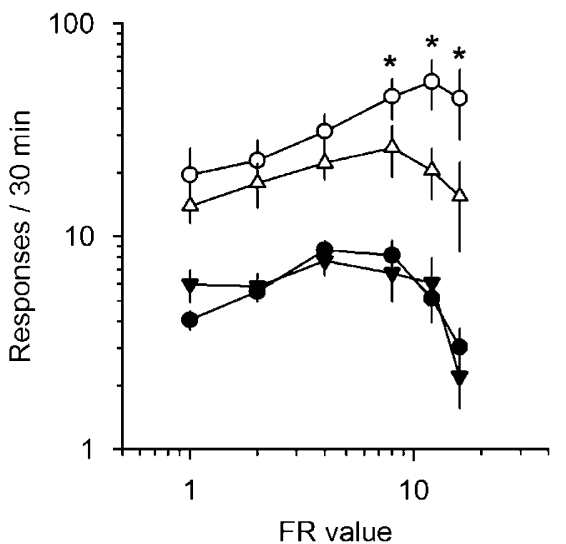

Figure 3 Effects of drug access time on heroin demand (a) and response output (b). Heroin demand was assessed in a within-session manner by increasing the fixed-ratio (FR) value (from I to I6). Each FR value was in effect during $30 \mathrm{~min}$. Data (mean \pm SEM) represent the average over the last three testing sessions of each food condition (ie no food vs concurrent food). Each testing session lasted $3 \mathrm{~h} 33 \mathrm{~min}$ and alternated across days with regular I-h (short access (ShA) rats, $n=10$ ) or 6-h (long access ( $\mathrm{LgA})$ rats, $n=9$ ) sessions of heroin self-administration. In LgA rats, the availability of food induced a leftward shift in $P_{\max }$ and a downward shift in $O_{\max }$, suggesting a reduction in the reinforcing effectiveness of heroin. *Different from the condition with concurrent food $(p<0.05)$. Note that in each condition and regardless of the prices, LgA rats took more heroin than ShA (see main text).

\section{Effects of Prolonged Access to Heroin on Elasticity of Demand}

As expected, heroin consumption decreased as price increased (FR value: $\mathrm{F}(5,85)=92.04, p<0.05$ ). Overall, however, LgA rats consumed more heroin and were less sensitive to price than ShA rats (group: $\mathrm{F}(1,17)=29.58$, $p<0.05 ;$ group $\times \mathrm{FR}$ value: $\mathrm{F}(5,85)=8.27, \quad p<0.05)$ (Figure $3 \mathrm{a}$ ). In addition, both groups responded differently to the concurrent availability of food (food condition $\times$ group: $F(1,17)=5.90, p<0.05)$. Separate two-way ANOVAs in each group revealed that the presence of food during heroin self-administration decreased heroin consumption only in $\operatorname{LgA}$ rats (food condition: $\mathrm{F}(1,8)=5.97$, $p<0.05$ ) but not in ShA rats. In LgA rats, the magnitude of this effect tended to increase with the FR value, but this interaction was not statistically significant. Note that similar results were obtained when heroin consumption was expressed in milligram per kilogram (data not shown).

Analyses of response rates confirmed these results (Figure $3 \mathrm{~b}$ ). With increasing FR values, response rate first increased, reached a peak and then decreased (FR value: $\mathrm{F}(5,85)=5.12, p<0.05)$. Overall, however, response rate in LgA rats was shifted upward compared to ShA rats (group: $\mathrm{F}(1,17)=16.31, p<0.05)$. Again groups responded differently in the presence of food during heroin self-administration (food condition $\times$ group $\times F R$ value: $F(5,85)=3.17$, $p<0.05)$. Separate two-way ANOVAs in each group revealed that in LgA rats but not in ShA rats, the availability of food induced a decrease in response rate (food condition: $\mathrm{F}(1,8)=5.97, p<0.05$ ) that was price-dependent (food condition $\times$ FR value: $\mathrm{F}(5,40)=2.98, p<0.05)$. 

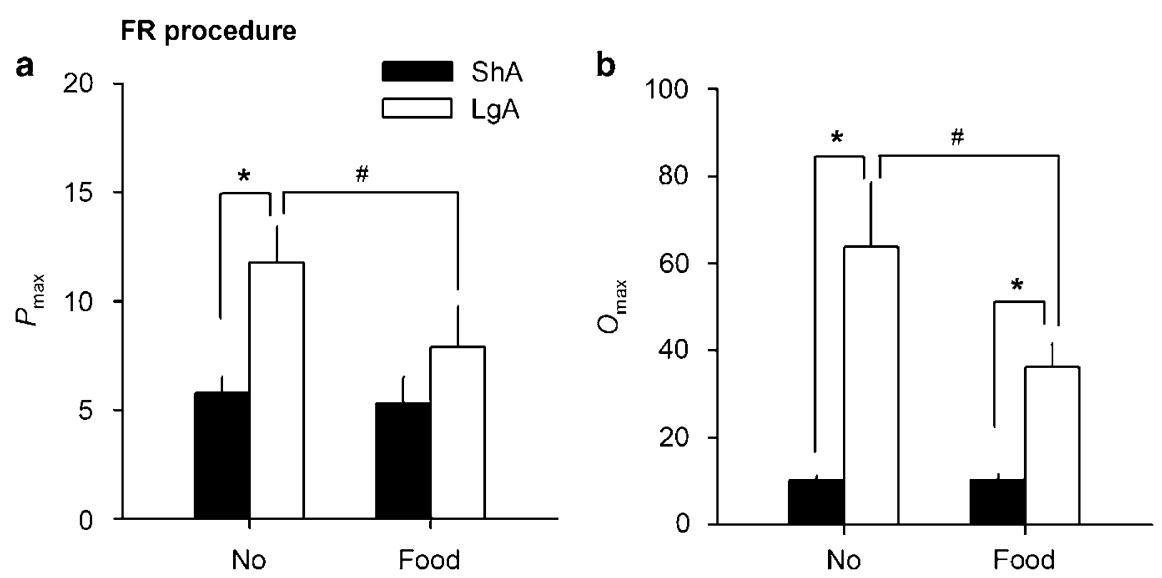

Figure 4 Effects of drug access time on $P_{\max }(a)$ and $O_{\max }(b) . P_{\max }$ and $O_{\max }$ values were estimated graphically from individual response output curves (see Figure I). Data (mean \pm SEM) represent the average over the last three testing sessions of each food condition (no food vs concurrent food). * Different from short access $(\mathrm{ShA})$ rats $(p<0.05) ;{ }^{\#}$ Different from the condition with concurrent food $(p<0.05)$.
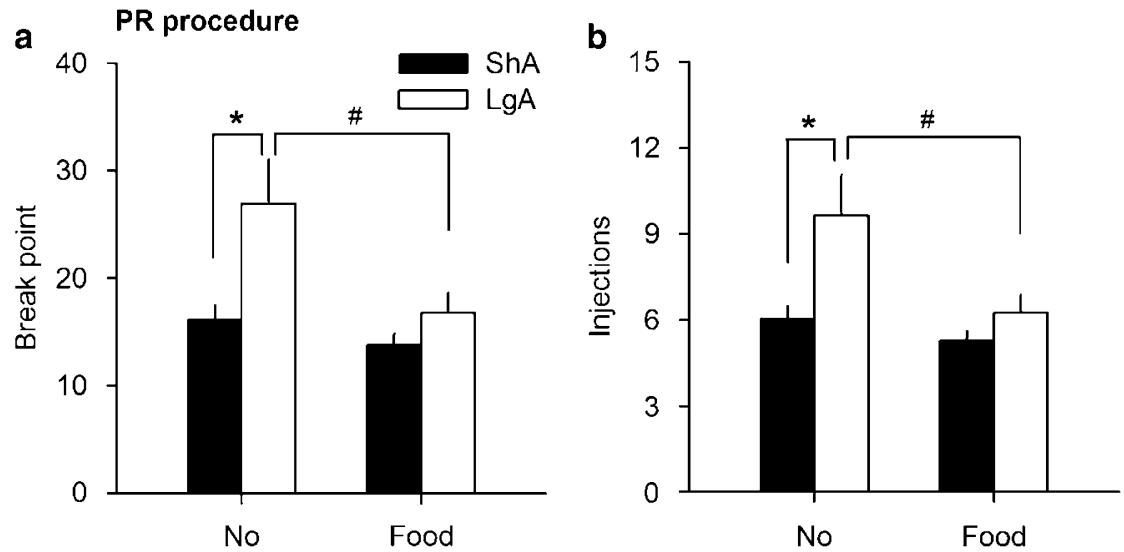

Figure 5 Effects of drug access time on the break point for heroin self-administration (a) and the final number of injections (b). Data (mean \pm SEM) represent the average over the last three testing sessions of each food condition (no food vs concurrent food). Response requirements were linearly increased by three (PR3) following each heroin injection (ie I, 4, 7, 10 and so on). Each progressive-ratio (PR) session ended when 30 min elapsed without an injection and alternated across days with regular I-h (short access (ShA) rats, $n=10$ ) or 6-h (long access (LgA) rats, $n=9)$ sessions of heroin selfadministration. *Different from either ShA rats $(p<0.05)$; " Different from the condition with concurrent food $(p<0.05)$.

Data presented in Figure 3 do not allow a statistical analysis of differences in $P_{\max }$ between groups. To conduct this analysis, we first estimated in each subject individually its $O_{\max }$ and $P_{\max }$ values (see Materials and Methods) and then compared these values between groups. Both $P_{\max }$ $(\mathrm{F}(1,17)>6.37, p<0.05)$ and $O_{\max }(\mathrm{F}(1,17)>18.95, p<0.05)$ were increased in LgA rats compared to ShA rats (Figure 4). In addition, the concurrent availability of food during heroin access tended to differentially affect $P_{\max }$ across groups (food condition: $\mathrm{F}(1,17)=4.34, p=0.052$ ) (Figure 4a). Post hoc comparisons revealed that food significantly reduced $P_{\max }$ in LgA rats (Fisher's LSD test, $p<0.05$ ) but was without effect in ShA rats. Similarly, depending on the group, food had a differential effect on $O_{\max }$ (food condition: $\mathrm{F}(1,17)=6.00$, $p<0.05$; group $\times$ food condition: $\mathrm{F}(1,17)=6.08, p<0.05)$ (Figure 4b). Post hoc comparisons revealed that food significantly reduced $O_{\max }$ in LgA rats (Fisher's LSD test, $p<0.05$ ) but had no effect on $O_{\max }$ in ShA rats.

As expected, in the PR procedure, LgA rats took more heroin (Figure 5a) and attained a higher break point than
ShA rats (Figure 5b) $(\mathrm{F}(1,17)=4.84, p<0.05)$. As with $P_{\max }$ and $O_{\max }$, the availability of food had a differential effect on both PR measures according to the experimental group $(\mathrm{F}(1,17)=17.59, \quad p<0.05 ; \quad$ group $\times$ food condition: $\mathrm{F}(1,17)=6.96, p<0.05)$. Post hoc comparisons revealed that food significantly reduced both PR measures in LgA rats (Fisher's LSD test, $p<0.05$ ) but had no effect on these measures in ShA rats. Interestingly, when no food was available, the break point for heroin self-administration was positively correlated with both $P_{\max }(r=0.56, p<0.05)$ and $O_{\max }(r=0.46, p<0.05)$. In contrast, when food was available, the break point was not significantly correlated with $P_{\max }$ or $O_{\max }(r<0.2)$.

\section{Food Intake During Heroin Self-Administration}

Under the FR procedure, LgA rats ate more food when available than ShA rats (average intake over last three sessions \pm SEM: LgA rats, $26.0 \pm 2.8 \mathrm{~g} / \mathrm{kg}$; ShA rats, $18.2 \pm 1.2 \mathrm{~g} / \mathrm{kg}) \quad(\mathrm{F}(1,17)=7.29, p<0.05)$. Under the $\mathrm{PR}$ 
procedure, however, there was no significant difference between groups in food intake (average intake over last three sessions \pm SEM: $\operatorname{LgA}$ rats, $11.5 \pm 2.6$; ShA rats, $12.1 \pm 0.8 \mathrm{~g} / \mathrm{kg})$.

A total four out of nine $\operatorname{LgA}$ rats were given food during prolonged access to heroin self-administration to prevent the occurrence of self-mutilation (for details, see Materials and Methods). A three-way ANOVA performed on the FR data obtained in $\mathrm{LgA}$ rats revealed a significant subgroup (food preexposed; non-preexposed) $\times$ FR value $\times$ food condition interaction $(F(5,35)=3.08, p<0.05)$. Subsequent separate two-way ANOVAs in each food condition, however, did not reveal any significant difference between LgA subgroups (not shown). Similarly, regardless of the food condition, there was no significant difference between LgA subgroups in the PR procedure (not shown). Finally, note that food-preexposed LgA rats ate the same amount of food as non-preexposed rats during both the FR $(26.9 \pm 4.0 \mathrm{vs}$ $25.4 \pm 4.2 \mathrm{~g})$ and $\mathrm{PR}$ procedures $(14.1 \pm 4.3$ vs $8.4 \pm 1.4 \mathrm{~g})$.

\section{DISCUSSION}

Animals with prolonged access to heroin self-administration (LgA rats) rapidly escalated their heroin intake over time and above that of rats with more limited access to the drug (ShA rats). This finding reproduces previous research on prolonged or unlimited access to opiate self-administration in rats (Bozarth and Wise, 1985; Ahmed et al, 2000; Morgan et al, 2002; Walker et al, 2003; Kenny et al, 2006; Chen et al, 2006; Lenoir and Ahmed, 2007), monkeys (Deneau et al, 1969; Woods and Schuster, 1971) and humans (Wikler, 1952). After escalation, increasing heroin prices decreased heroin consumption in both groups of animals. However, despite increased prices, LgA rats continued to take more heroin than ShA rats. In addition, heroin consumption was more inelastic in $\operatorname{LgA}$ rats than in ShA rats, as shown by an increased $P_{\max }$. This increase in $P_{\max }$ was associated with a concurrent increase in the break point for heroin self-administration, as measured under the PR procedure. Together these findings strongly suggest that the inelasticity of heroin demand increases during escalation of heroin self-administration and that heroin has acquired greater reinforcing strength. Finally, supplying food during access to heroin tended to reverse the increased inelasticity of heroin demand in LgA rats. In contrast, food had no significant impact on the demand elasticity of heroin in ShA rats. Thus, the increased inelasticity of heroin demand seen in drug-escalated individuals is associated with an increase in sensitivity to nondrug substitutes and not with a decrease, as was originally predicted.

Previous research showed that extended access to heroin self-administration is associated with an increased difficulty to stop heroin seeking when the drug is no longer available (Ahmed et al, 2000; Lenoir and Ahmed, 2007). This increased resistance to extinction was interpreted as evidence for an increase in the value of heroin. The present findings directly support this interpretation. LgA rats were more likely than ShA rats to defend their heroin consumption as price increased. As a result, they achieved a higher $O_{\max }$ and a greater $P_{\max }$ than ShA rats, indicating that heroin demand became inelastic over a wider range of prices after escalation. Since an inelastic demand characterizes commodities that are essential for the survival and/ or well-being of the individual (Lea, 1978; Hursh, 1980), this observation suggests that heroin acquired greater reinforcing effectiveness as escalation progressed. Consistent with this interpretation, the break point for heroin self-administration - a classic measure of the strength of motivation (Hodos, 1961; Arnold and Roberts, 1997) - increased following prolonged access to heroin self-administration. This finding confirms and extends to heroin self-administration previous findings in rats (Carrera et al, 1999) and in monkeys (Yanagita, 1978) after chronic morphine administration.

Here, it is interesting to comment on the fact that the break point was positively correlated with $P_{\max }$ in the present study ( $r=0.56$, no food available), an outcome that adds support to the hypothesis that these two behavioral variables are analogous and measure the reinforcing strength of drugs (Rodefer and Carroll, 1997; Bickel et al, 2000; Greenwald and Hursh, 2006). However, the similarity of outcomes between the FR and PR procedures could also result from procedural similarities. In our FR procedure, FR values were presented within-session every $33 \mathrm{~min}$ and in a progressive ascending order, making our FR procedure an interval variant of the $\mathrm{PR}$ procedure. This latter feature could also explain why it was not possible to calculate $P_{\max }$ from the present FR data using the equation originally developed by Hursh et al (1988). This equation indeed provides a good description of most demand curves obtained by presenting FR values between-sessions and in a mixed order. Future studies will be needed to determine the exact impact of these procedural differences on the goodness-of-fit of Hursh's equation to drug demand curves.

As explained in the introduction, an increased inelasticity of drug demand can theoretically result from a decreased sensitivity to nondrug substitutes. To test this hypothesis, we measured the effects of a food substitute on heroin demand in both ShA and LgA rats. Contrary to theoretical predictions, however, the demand for heroin was more sensitive to the availability of food in LgA rats than in ShA rats. Specifically, supplying food tended to reverse the increased inelasticity of heroin demand in $\operatorname{LgA}$ rats, as evidenced by a decrease in $P_{\max }$, but was without effect on the demand for heroin in ShA rats. Similarly, in the PR procedure, supplying food returned the elevated break point to normal in LgA rats but had no consequence in ShA rats. As a whole, these observations clearly showed that food consumption can act as a potent substitute for heroin use in individuals that have escalated their heroin use, confirming and extending to heroin intake escalation previous research on other drugs of abuse (Carroll et al, 1991, 1995; Comer et al, 1996; Rodefer and Carroll, 1996, 1997).

The lack of any beneficial effect of food on heroin demand in ShA rats was unexpected and is difficult to interpret. First, it is possible that ShA rats were indifferent to the availability of food during heroin self-administration. This explanation is unlikely because ShA rats ate a significant amount of food during testing, showing that they were both sensitive to its presence and interested in eating it. Second, the lack of effects of food on heroin demand in ShA rats could also reflect a lack of sensitivity of the procedure. Heroin consumption was relatively low in 
ShA rats (less than four doses per $30 \mathrm{~min}$ at the lowest price), thereby leaving little room for an additional decrease in consumption produced by the supply of food. In other words, the relative lack of effects of food in ShA rats could simply result from a floor effect. Finally, the lack of effects of food on the elasticity of heroin demand in ShA rats could merely indicate that food is poorly substitutable for heroin in these animals. As suggested below, the function of food as a substitute for heroin may be acquired secondarily after prolonged, but not limited, access to heroin self-administration.

The increased sensitivity of $\operatorname{LgA}$ rats to the beneficial effects of food on heroin consumption suggests that prolonged heroin use did not decrease, as expected, but instead increased the substitutability between heroin and food. This conclusion is partially consistent with experimental evidence showing the efficacy of alternative reinforcement in reducing the demand for heroin in dependent individuals (Comer et al, 1997, 1998; Heishman et al, 2000). It is also consistent with previous studies in laboratory animals showing that drug addiction-prone rats are paradoxically more sensitive to alternative rewards than less vulnerable individuals (Cosgrove et al, 2002; Cosgrove and Carroll, 2003). For instance, Carroll et al have recently shown that wheel running was a better substitute for cocaine in female rats than in male rats (Cosgrove et al, 2002), despite the fact that cocaine is a more effective reinforcer in females than in males as measured under both FR and PR procedures (Carroll et al, 2004). Taken together, these different studies show that substitutability between drug and nondrug rewards does not decrease, but instead tends to increase, in drug addiction-prone or drug-addicted rats.

This general conclusion appears, however, to conflict with previous research in opioid-dependent monkeys showing that opioid withdrawal decreased the ability of food to substitute for heroin (Negus, 2006) or morphine (Spragg, 1940; Griffiths et al, 1975). For instance, Negus (2006) recently demonstrated using a discrete-trials choice procedure in monkeys that withdrawal from prolonged access to heroin self-administration is associated with an increased preference for heroin that was temporarily correlated with the emergence of physical signs of opioid withdrawal. In the present study, no attempt was made to measure physical signs of opioid withdrawal in LgA rats. Nevertheless, there was strong indirect evidence for opioid dependence with prolonged access to heroin in that LgA rats gained much less weight than ShA rats during escalation $(+24.4 \pm 4.5 \mathrm{vs}$ $+104.3 \pm 4.2 \mathrm{~g}$, means $\pm \mathrm{SEM}$; see also Figure 6 in Lenoir and Ahmed, 2007). In support of this interpretation, Chen et al (2006) have recently shown that rats with unlimited access to heroin self-administration become physically dependent and show a reduction in both food intake and body weight gain compared to non-dependent controls. Note that the retardation of body weight gain seen in LgA rats in the present study did not simply result from a shorter daily access to food (due to a longer daily access to heroin) relative to ShA rats, since LgA rats with food access during heroin self-administration (lost $5 \mathrm{~h}$ ) gained as much weight as LgA rats without access to food $(+25.5 \pm 7.2 \mathrm{vs}$ $+23.6 \pm 6.6 \mathrm{~g})$. Thus, the apparent discrepancy between the present study and previous studies in opioid dependent monkeys is unlikely attributable to an absence of physical dependence in LgA rats and may instead reflect differences in dependence intensity between studies. Additional research is needed to address this important issue.

The present study shows that escalation of heroin consumption - a hallmark of drug addiction - is associated with a concomitant augmentation of both the reinforcing strength of heroin and of its substitutability with food. The increased sensitivity to food observed in LgA rats may be confounded, however, by decreased body weight gain and/ or food intake associated with heroin dependence (see above). Specifically, it could be argued that the ability of food to compete with heroin when available was greater in LgA rats than in ShA rats simply because LgA rats were underfed. Partially consistent with this suggestion, we found that $\operatorname{LgA}$ rats ate more food than ShA rats during the FR procedure. It is thus possible that the differential effect of food between groups would disappear if the present study had restricted access to food in ShA rats to maintain their body weight similar to that of LgA rats. Though additional research is needed to clarify this issue, it should be pointed out that restricting access to food in ShA rats will introduce another confounding factor, since food restriction can induce drug intake escalation by itself (eg Carroll et al, 1979). In addition, increased food intake by $\operatorname{LgA}$ rats during the FR procedure could also reflect increased heroin consumption and not necessarily an underfed state, as opiates directly stimulate feeding (Glass et al, 1999). Finally, it is important to consider that lowered body weight appears to be intrinsic to opiate dependence in both humans (Santolaria-Fernandez et al, 1995) and animals (Chen et al, 2006; Lenoir and Ahmed, 2007) and, as such, is probably not a confounding variable.

A more valid approach than food restriction would be to use a non-nutritive substitute for drugs, such as, for instance, a drink containing a calorie-free sweetener. This approach has the additional advantage of controlling for gnawing - a frequent behavior specifically engendered by LgA to heroin self-administration - that may have confounded the present study (Pollock and Kornetsky, 1989; Lenoir and Ahmed, 2007). For instance, it is possible that LgA rats showed reduced heroin demand in the presence of food, not because of the increased value of food (as presumed here), but because food pellets would allow LgA rats to gnaw and to relieve an 'akathisia-like' effect induced by escalated heroin intake. However, previous research has shown that nutrition or gnawing per se is not necessary for substitutability between food and drugs because nongnawable, calorie-free sweetened drinks can substitute for drugs of abuse in both rats and monkeys (Carroll, 1993). In addition, the akathisia reduction hypothesis would predict that food access during extended access to high doses of heroin should increase the beneficial effects of food on heroin demand, but this effect was not observed in the subgroup of LgA rats preexposed to food (see Results). Finally, we recently found using a discrete-trials choice procedure that water sweetened with saccharin can substitute for, and even surpass, cocaine (Lenoir et al, 2007) or heroin reward after drug intake escalation (Lenoir and Ahmed, submitted). As a whole, these findings suggest that nutrition and gnawing were probably not significant confounding factors in the present study.

Finally, another potential limitation of the present study is that different doses of heroin were used for ShA rats 
$(15 \mu \mathrm{g})$ and $\mathrm{LgA}$ rats $(15 \mu \mathrm{g}$ for the first hour and $60 \mu \mathrm{g}$ for the lost $5 \mathrm{~h}$ ) on maintenance days. This procedure was used to speed up escalation of heroin intake by $\operatorname{LgA}$ rats (Mantsch et al, 2004; Lenoir and Ahmed, 2007). However, it has the disadvantage of confounding dose with time of access. As a result, it is difficult to know whether LgA rats responded more for heroin than ShA rats because they had access to a higher dose of heroin or to a longer session of self-administration. For instance, it could be argued that the significant negative contrast between the low dose of heroin available during the first hour of each 6-h session and the higher dose available subsequently would explain why LgA rats were taking more heroin and were working harder than ShA rats. This explanation is unlikely here, however, as successive negative contrasts between rewards (ie a small reward preceding a larger one) generally lead to a reduction, not an augmentation, in the intake of and motivation for the smaller, earlier reward (Crespi, 1942; Flaherty, 1999).

In summary, this study shows that heroin intake escalation is associated with an increased inelasticity of heroin demand. However, supplying a nondrug substitute during heroin access was sufficient to reverse this increase in demand inelasticity. Thus, contrary to theoretical predictions, increased inelasticity of heroin demand in drug-escalated individuals was not associated with a decrease, as expected, but instead with an increase in sensitivity to nondrug substitutes. Future research is needed to better understand this phenomenon. Nevertheless, these observations clearly show that individuals with escalating heroin use - a hallmark of drug addiction-are still behaviorally sensitive to competing nondrug rewards. In light of this finding, one can speculate that escalated drug use in drug addicts may persist, not so much because of a loss of efficacy of nondrug substitutes but because of a loss or reduction of their availability. Combining increased drug prices with increased accessibility to nondrug substitutes may therefore provide a powerful approach to reduce drug use in drug-addicted individuals, as already demonstrated by the clinical efficacy of contingency management therapy in the treatment of drug addiction (Higgins et al, 2004; Carroll and Onken, 2005; Stitzer and Petry, 2006).

\section{ACKNOWLEDGEMENTS}

This work was supported by the Université Victor-Segalen Bordeaux 2, the French Research Council (CNRS), the Conseil Regional d'Aquitaine, the Mission Interministérielle de Lutte contre la Drogue et la Toxicomanie (MILDT), the National Research Agency (ANR) and the Fondation pour la Recherche Médicale (FRM). We thank Anne Fayoux and Stephane Lelgouach for animal care, Pierre Gonzalez for technical assistance, Marie-Hélène Bruyères for administrative assistance, Caroline Vouillac for logistic assistance, Christian Darrack for his help with data extraction, Alain Labarriere for house-keeping assistance and, finally, $\mathrm{Dr}$ Martine Cador for general support. We also thank the reviewers for their constructive comments.

\section{DISCLOSURE/CONFLICT OF INTEREST}

The authors declare no financial conflict of interest.

\section{REFERENCES}

Ahmed SH (2004). Neuroscience. Addiction as compulsive reward prediction. Science 306: 1901-1902.

Ahmed SH (2005). Imbalance between drug and non-drug reward availability: a major risk factor for addiction. Eur J Pharmacol 526: 9-20.

Ahmed SH, Cador M (2006). Dissociation of psychomotor sensitization from compulsive cocaine consumption. Neuropsychopharmacology 31: 563-571.

Ahmed SH, Kenny PJ, Koob GF, Markou A (2002). Neurobiological evidence for hedonic allostasis associated with escalating cocaine use. Nat Neurosci 5: 625-626.

Ahmed SH, Koob GF (1998). Transition from moderate to excessive drug intake: change in hedonic set point. Science 282: 298-300.

Ahmed SH, Koob GF (1999). Long-lasting increase in the set point for cocaine self-administration after escalation in rats. Psychopharmacology 146: 303-312.

Ahmed SH, Walker JR, Koob GF (2000). Persistent increase in the motivation to take heroin in rats with a history of drug escalation. Neuropsychopharmacology 22: 413-421.

Allison J (1979). Demand economics and experimental psychology. Behav Sci 24: 403-415.

Arnold JM, Roberts DC (1997). A critique of fixed and progressive ratio schedules used to examine the neural substrates of drug reinforcement. Pharmacol Biochem Behav 57: 441-447.

Bauman RA, Raslear TG, Hursh SR, Shurtleff D, Simmons L (1996). Substitution and caloric regulation in a closed economy. J Exp Anal Behav 65: 401-422.

Bickel WK, DeGrandpre RJ, Higgins ST (1995). The behavioral economics of concurrent drug reinforcers: a review and reanalysis of drug self-administration research. Psychopharmacology 118: 250-259.

Bickel WK, DeGrandpre RJ, Higgins ST, Hughes JR (1990). Behavioral economics of drug self-administration. I. Functional equivalence of response requirement and drug dose. Life Sci 47: $1501-1510$.

Bickel WK, Marsch LA, Carroll ME (2000). Deconstructing relative reinforcing efficacy and situating the measures of pharmacological reinforcement with behavioral economics: a theoretical proposal. Psychopharmacology 153: 44-56.

Bozarth MA, Wise RA (1985). Toxicity associated with long-term intravenous heroin and cocaine self-administration in the rat. JAMA 254: 81-83.

Carrera MR, Schulteis G, Koob GF (1999). Heroin self-administration in dependent Wistar rats: increased sensitivity to naloxone. Psychopharmacology 144: 111-120.

Carroll KM, Onken LS (2005). Behavioral therapies for drug abuse. Am J Psychiatry 162: 1452-1460.

Carroll ME (1993). The economic context of drug and non-drug reinforcers affects acquisition and maintenance of drug-reinforced behavior and withdrawal effects. Drug Alcohol Depend 33: 201-210.

Carroll ME, Carmona GG, May SA (1991). Modifying drugreinforced behavior by altering the economic conditions of the drug and a nondrug reinforcer. J Exp Anal Behav 56: 361-376.

Carroll ME, France CP, Meisch RA (1979). Food deprivation increases oral and intravenous drug intake in rats. Science 205: 319-321.

Carroll ME, Lynch WJ, Roth ME, Morgan AD, Cosgrove KP (2004). Sex and estrogen influence drug abuse. Trends Pharmacol Sci 25: 273-279.

Carroll ME, Rodefer JS, Rawleigh JM (1995). Concurrent selfadministration of ethanol and an alternative nondrug reinforcer in monkeys: effects of income (session length) on demand for drug. Psychopharmacology 120: 1-9.

Chen SA, O'Dell LE, Hoefer ME, Greenwell TN, Zorrilla EP, Koob GF (2006). Unlimited access to heroin self-administration: 
independent motivational markers of opiate dependence. Neuropsychopharmacology 31: 2692-2707.

Collier G, Johnson DF (2000). Sucrose intake as a function of its cost and the cost of chow. Physiol Behav 70: 477-487.

Comer SD, Collins ED, Fischman MW (1997). Choice between money and intranasal heroin in morphine-maintained humans. Behav Pharmacol 8: 677-690.

Comer SD, Collins ED, Wilson ST, Donovan MR, Foltin RW, Fischman MW (1998). Effects of an alternative reinforcer on intravenous heroin self-administration by humans. Eur $J$ Pharmacol 345: 13-26.

Comer SD, Lac ST, Wyvell CL, Carroll ME (1996). Combined effects of buprenorphine and a nondrug alternative reinforcer on i.v. cocaine self-administration in rats maintained under FR schedules. Psychopharmacology 125: 355-360.

Cosgrove KP, Carroll ME (2003). Effects of a non-drug reinforcer, saccharin, on oral self-administration of phencyclidine in male and female rhesus monkeys. Psychopharmacology 170: 9-16.

Cosgrove KP, Hunter RG, Carroll ME (2002). Wheel-running attenuates intravenous cocaine self-administration in rats: sex differences. Pharmacol Biochem Behav 73: 663-671.

Crespi LP (1942). Quantitative variation in incentive and performance in the white rat. Am J Psychol 55: 467-517.

Deneau G, Yanagita T, Seevers MH (1969). Self-administration of psychoactive substances by the monkey. Psychopharmacologia 16: $30-48$

Eatherly J (1974). Drug-law enforcement: should arrest pushers or users? J Political Economy 82: 210-214.

Ferrario CR, Gorny G, Crombag HS, Li Y, Kolb B, Robinson TE (2005). Neural and behavioral plasticity associated with the transition from controlled to escalated cocaine use. Biol Psychiatry 58: 751-759.

Flaherty CF (1999). Incentive Relativity. Cambridge University Press: New York.

Glass MJ, Billington CJ, Levine AS (1999). Opioids and food intake: distributed functional neuronal pathways? Neuropeptides 33: 360-368.

Greenwald MK, Hursh SR (2006). Behavioral economic analysis of opioid consumption in heroin-dependent individuals: effects of unit price and pre-session drug supply. Drug Alcohol Depend 85: $35-48$.

Griffiths RR, Wurster RM, Brady JV (1975). Discrete-trial choice procedure: effects of naloxone and methadone on choice between food and heroin. Pharmacol Rev 27: 357-365.

Heishman SJ, Schuh KJ, Schuster CR, Henningfield JE, Goldberg SR (2000). Reinforcing and subjective effects of morphine in human opioid abusers: effect of dose and alternative reinforcer. Psychopharmacology 148: 272-280.

Heyman GM (1996). Resolving the contradictions of addiction. Behav Brain Sci 19: 561-610.

Heyman GM, Gendel K, Goodman J (1999). Inelastic demand for alcohol in rats. Psychopharmacology 144: 213-219.

Higgins ST, Heil SH, Lussier JP (2004). Clinical implications of reinforcement as a determinant of substance use disorders. Annu Rev Psychol 55: 431-461.

Hodos W (1961). Progressive ratio as a measure of reward strength. Science 134: 943-944.

Hursh SR (1980). Economic concepts for the analysis of behavior. J Exp Anal Behav 34: 219-238.

Hursh SR (1991). Behavioral economics of drug selfadministration and drug abuse policy. J Exp Anal Behav 56: 377-393.

Hursh SR, Raslear TG, Shurtleff D, Bauman R, Simmons L (1988). A cost-benefit analysis of demand for food. J Exp Anal Behav 50: 419-440.

Johanson CE, Balster RL, Bonese K (1976). Self-administration of psychomotor stimulant drugs: the effects of unlimited access. Pharmacol Biochem Behav 4: 45-51.
Kenny PJ, Chen SA, Kitamura O, Markou A, Koob GF (2006). Conditioned withdrawal drives heroin consumption and decreases reward sensitivity. J Neurosci 26: 5894-5900.

Ko MC, Terner J, Hursh S, Woods JH, Winger G (2002). Relative reinforcing effects of three opioids with different durations of action. J Pharmacol Exp Ther 301: 698-704.

Lea SEG (1978). The psychology and economics of demand. Psychol bull 85: 441-466.

Lea SEG, Roper TJ (1977). Demand for food on fixed-ratio schedules as a function of the quality of concurrently available reinforcement. J Exp Anal Behav 27: 371-380.

Lenoir M, Ahmed SH (2007). Heroin-induced reinstatement is specific to compulsive heroin use and dissociable from heroin reward and sensitization. Neuropsychopharmacology 32: 616-624.

Lenoir M, Serre F, Cantin L, Ahmed SH (2007). Intense sweetness surpasses cocaine reward. PLOS ONE 2: e698. doi:10.1371/ journal.pone.0000698.

Liu Y, Roberts DC, Morgan D (2005). Effects of extended-access self-administration and deprivation on breakpoints maintained by cocaine in rats. Psychopharmacology 179: 644-651.

Mantsch JR, Ho A, Schlussman SD, Kreek MJ (2001). Predictable individual differences in the initiation of cocaine self-administration by rats under extended-access conditions are dosedependent. Psychopharmacology 157: 31-39.

Mantsch JR, Yuferov V, Mathieu-Kia AM, Ho A, Kreek MJ (2004). Effects of extended access to high versus low cocaine doses on self-administration, cocaine-induced reinstatement and brain mRNA levels in rats. Psychopharmacology 175: 26-36.

Miron JA, Zwiebel J (1995). The economic case against drug prohibition. J Econ Perspect 9: 175-192.

Morgan D, Brebner K, Lynch WJ, Roberts DC (2002). Increases in the reinforcing efficacy of cocaine after particular histories of reinforcement. Behav Pharmacol 13: 389-396.

Negus SS (2006). Choice between heroin and food in nondependent and heroin-dependent rhesus monkeys: effects of naloxone, buprenorphine, and methadone. J Pharmacol Exp Ther 317: 711-723.

Paterson NE, Markou A (2003). Increased motivation for selfadministered cocaine after escalated cocaine intake. Neuroreport 14: 2229-2232.

Perry JL, Morgan AD, Anker JJ, Dess NK, Carroll ME (2006). Escalation of i.v. cocaine self-administration and reinstatement of cocaine-seeking behavior in rats bred for high and low saccharin intake. Psychopharmacology 186: 235-245.

Pollock J, Kornetsky C (1989). Evidence for the role of dopamine D1 receptors in morphine induced stereotypic behavior. Neurosci Lett 102: 291-296.

Roberts DC, Bennett SA (1993). Heroin self-administration in rats under a progressive ratio schedule of reinforcement. Psychopharmacology 111: 215-218.

Rodefer JS, Carroll ME (1996). Progressive ratio and behavioral economic evaluation of the reinforcing efficacy of orally delivered phencyclidine and ethanol in monkeys: effects of feeding conditions. Psychopharmacology 128: 265-273.

Rodefer JS, Carroll ME (1997). A comparison of progressive ratio schedules versus behavioral economic measures: effect of an alternative reinforcer on the reinforcing efficacy of phencyclidine. Psychopharmacology 132: 95-103.

Samuelson PA, Nordhaus WD (1998). Economics, 16th edn. IrwinMcGraw-Hill: Boston.

Santolaria-Fernandez FJ, Gomez-Sirvent JL, Gonzalez-Reimers CE, Batista-Lopez JN, Jorge-Hernandez JA, Rodriguez-Moreno F et al (1995). Nutritional assessment of drug addicts. Drug Alcohol Depend 38: 11-18.

Solinas M, Panlilio LV, Goldberg SR (2004). Exposure to delta-9tetrahydrocannabinol (THC) increases subsequent heroin taking but not heroin's reinforcing efficacy: a self-administration study in rats. Neuropsychopharmacology 29: 1301-1311. 
Reversal of escalated heroin use M Lenoir and SH Ahmed

Spragg SD (1940). Morphine addiction in chimpanzees. Comp Psychol Monogr 15: 1-132.

Stitzer M, Petry N (2006). Contingency management for treatment of substance abuse. Ann Rev Clin Psychol 2: 411-434.

Walker JR, Chen SA, Moffitt H, Inturrisi CE, Koob GF (2003). Chronic opioid exposure produces increased heroin self-administration in rats. Pharmacol Biochem Behav 75: 349-354.

Wee S, Specio SE, Koob GF (2007). Effects of dose and session duration on cocaine self-administration in rats. J Pharmacol Exp Ther 320: 1134-1143.
Wikler A (1952). A psychodynamic study of a patient during experimental self-regulated re-addiction to morphine. Psychiatr Q 26: 270-293.

Wolffgramm J (1991). An ethopharmacological approach to the development of drug addiction. Neurosci Biobehav Rev 15: 515-519.

Woods JH, Schuster CR (1971). Opiates as reinforcing stimuli. In: Thompson T, Pickens R (eds). Stimulus Properties of Drugs. Appleton-Century-Crofts: New York. pp 163-175.

Yanagita T (1978). Drug dependence studies in laboratory animals. NIDA Res Monogr 19: 179-190. 